\section{International Scientific Journal Theoretical \& Applied Science}

\author{
p-ISSN: 2308-4944 (print) e-ISSN: 2409-0085 (online) \\ Year: 2017 Issue: 04 Volume: 48 \\ Published: $30.04 .2017 \quad$ http://T-Science.org
}

Svetlana Anatol'evna Balyaeva Professor, Doktor of Pedagogical Science,

Professor Department of Physics, State Maritime University Admiral Ushakov,Russia, sergei_mishik@mail.ru

SECTION 21. Pedagogy. Psychology. Innovation in Education

\title{
DIDACTIC MEANS OF BASIC TRAINING OF FLOATING IN THE SEA UNIVERSITY
}

Abstract: The ways of modernization of didactic means of basic training of specialists of the seafarers on the basis of innovative methodical technologies with computer support are highlighted.

Key words: didactic means, basic training, academic discipline, fundamentalization and professionalization of knowledge, computer technologies.

Language: Russian

Citation: Balyaeva SA (2017) DIDACTIC MEANS OF BASIC TRAINING OF FLOATING IN THE SEA UNIVERSITY. ISJ Theoretical \& Applied Science, 04 (48): 151-153.

Soi: http://s-o-i.org/1.1/TAS-04-48-24 Doi: crossef https://dx.doi.org/10.15863/TAS.2017.04.48.24

УДК 372.851

\section{ДИДАКТИЧЕСКИЕ СРЕДСТВА БАЗОВОЙ ПОДГОТОВКИ ПЛАВСОСТАВА В МОРСКОМ УНИВЕРСИТЕТЕ}

Аннотация: Выделены пути модернизации дидактических средств базовой подготовки специалистов плавсостава на основе инновационных методических технологий с компьютерной поддержкой.

Ключевые слова: дидактические средства, базовая подготовка, учебная дисчиплина, фундаментализация и профессионализащчия знаний, компьютерные технологии.

\section{Introduction}

Одной из ведущих тенденций развития современной образовательной ситуации, сложившейся на фоне активных инновационных процессов в социальной и экономической сферах жизни общества, является переход к информатизации образования. Осуществление информатизации образования требует особой государственной информационной политики, предусматривающей создание современной национальной информационной среды и интеграции в нее учреждений образования. Внедрение информационных технологий в учебный процесс становится необходимым условием повышения эффективности подготовки специалистов в высших учебных заведениях.

\section{Materials and Methods}

Широкое использование компьютеров на морском флоте меняет характер труда плавсостава, что проецирует реформирование образовательного пространства в морской отрасли. Появление современной компьютерной и телекоммуникационной техники, мультимедиасистем и соответствующих методических инноваций требует новых подходов к реализации образовательной деятельности на всех этапах подготовки специалистов в морском университете, в том числе и на этапе базовой подготовки будущих командиров флота [ 1 ].

Модернизация необходима содержанию, методам и техническим средствам базовой подготовки, учебным планам, программам, учебной литературе. Один из способов решения этой проблемы состоит во внедрении в учебный процесс университета инновационных методических систем и технологий с компьютерной поддержкой, направленных на разрешение противоречий между потребностью базовых учебных дисциплин в электронных ресурсах и устаревшими средствами дидактического обеспечения. В этой связи процесс совершенствования дидактических средств на этапе базовой подготовки должен 
начинаться с внесения методически обоснованных изменений в содержание этих средств с адекватным отражением структуры, логики и специфики содержания конкретной предметной области и осуществляться на основе информационных технологий [ 2,3,4 ].

При этим в рамках дисциплинарной структуры необходимо наметить пути и выделить методы обеспечения комплексности, системности в изучении предметно-специфических структур и явлений, методы научно обоснованной интеграции содержания всех базовых учебных дисциплин в органически целостную систему содержания базовой подготовки специалистов в морском университете. Эти задачи и помогает решить фундаментализация содержания базовых учебных дисциплин, которая обеспечивает синтез, интеграцию конкретных предметноспецифических знаний и умений из соответствующих познавательных областей в единое органическое целое [ 5, 6 ].

Научно обоснованное построение содержания учебной дисциплины нельзя осуществлять только на основе науки, стоящей за изучаемой дисциплиной. Поскольку содержание учебного материала определяется целями обучения и функциями, которые оно призвано выполнять в процессе обучения, то при формировании содержания учебного предмета следует опираться не только на логику соответствующей науки, но и на логику усвоения и закономерности процесса, в котором это содержание реализуется [ $3,7,8]$.

Нам представляется, что главный акцент должен делаться на способе организации ориентировки в предмете изучения. При этом разработка содержания как этой ориентировки, так и дидактических средств должна иметь профессиональную направленность и основываться на методических принципах системного подхода и, в первую очередь, - на принципе системного представления изучаемого объекта или процесса. Это позволит студентам понять и усвоить не только определенные теоретические закономерности, но и модель формируемой деятельности, уяснить ее строение и способ организации. При этом необходимо, чтобы содержание дидактических средств отражало не только знания о предмете, но и знания о строении деятельности ( составе, функциональной структуре ), способах выполнения деятельности.

Разработанное нами дидактическое обеспечение дисциплин базового цикла на примере дисциплины «Физика» базируется на принципе единства фундаментализации и профессионализации знаний о предмете. В экспериментальной технологии обучения особое значение придается формированию у студентов системной ориентировки в предмете изучения с рефлексией метода ее выделения. Основу технологии составляет общая схема ориентировочной основы деятельности [ 5,6 ].

Для оптимизации этой технологии необходимо предусмотреть эффективную компьютерную поддержку самостоятельной учебной работы студентов.

Внедрение компьютерных технологий в учебный процесс позволяет выстраивать дидактическую систему обучения по следующей схеме: ПРЕПОДАВАТЕЛЬ - информатизация методика - телекоммуникации - компьютер СТУДЕНТ [ 9 ].

При этом открытие доступа к электронным дидактическим ресурсам, входящим в учебный курс, обеспечивает оперативное введение студентов в содержательный контекст учебной дисциплины, организацию дистанционной консультативной помощи при выполнении учебных заданий, способствует формированию умения добывать информацию из удаленных источников, обрабатывать еe с помощью компьютерных средств, хранить и передавать по мере необходимости.

Применение педагогических технологий на базе электронных обучающих средств дает возможность реализации принципиально нового подхода к обучению и воспитанию личности будущего специалиста морского транспорта. Электронные образовательные ресурсы инициируют переход от иллюстративнообъяснительных методов и механического усвоения знаний к овладению умением самостоятельно приобретать новые знания, пользуясь современными способами представления и извлечения учебного материала и технологиями информационного взаимодействия в предметной среде. Это позволяет на этапе базовой подготовки формировать умение студентов работать с различными источниками информации, в том числе распределенными в локальных и глобальной мировой информационных сетях [ 10 , $11]$.

\section{Conclusion}

В заключение заметим, что модернизация дидактических средств за счет расширения сферы применения электронных образовательных ресурсов создает новые перспективы для использования в учебном процессе университета обучения в сотрудничестве. Тесное взаимодействие преподавателя и студента в процессе учебно-познавательной и научноисследовательской работы в условиях применения электронных обучающих ресурсов ведет к трансформации деятельности преподавателя и студентов, позволяет 
поддерживать высокую учебную мотивацию, поощрять личностные достижения, активность и инициативность студентов, что в конечном итоге способствует повышению качества базовой подготовки специалистов плавсостава для морского транспорта.

\section{References:}

1. Balyaeva SA, Uglova AN (2016) Innovatsionnyie vozmozhnosti organizatsii protsessa obucheniya po kursu fiziki $\mathrm{V}$ morskom universitete / V kn.: Obrazovanie i epoha ( aktualnaya nauchnaya paradigma ).Kniga 9.-Moskva: Nauka: inform; Voronezh: VGPU, 2016. p. 119-139.

2. Balyaeva SA, Uglova AN (2016) Tehnologicheskie podhodyi $\mathrm{k}$ proektirovaniyu soderzhaniya kursa fiziki v morskom vuze // Obschestvo : Sotsiologiya, Psihologiya, Pedagogika. Nauchnyiy zhurnal, \# 6.Krasnodar, 2016. p. 93-96.

3. Balyaeva SA (1999) Teoreticheskie osnovyi fundamentalizatsii obschenauchnoy podgotovki $\mathrm{v}$ sisteme vyisshego tehnicheskogo obrazovaniya. Avtoref. dis. d-ra ped. nauk. M..$32 \mathrm{p}$.

4. Reshetova ZA (1985) Psihologicheskie osnovyi professionalnogo obucheniya.-Moskva: Izd-vo Mosk. gos. un-ta. - 207 p.

5. Balyaeva SA, Borodina LN, Uglova AN (2008) Psihologo-pedagogicheskie osnovyi postroeniya uchebnoy distsiplinyi $\mathrm{v}$ tehnicheskom vuze // Vyisshee obrazovanie segodnya, \# 10, 2008. p. 23-27.

6. Balyaeva SA, Uglova AN (2014) Innovatsionnyie didakticheskie tehnologii kak sredstvo formirovaniya universalnyih professionalnyih kompetentsiy inzhenerov morskogo flota / V kn.: Obrazovatelnoinnovatsionnyie tehnologii: teoriya i praktika: monografiya / pod obschey red. prof. O.I.Kirikkova.- Kniga 19.- Moskva: Nauka: inform; Voronezh: VGPU, 2014. p.121-136.
7. Mischik SA (2015) Struktura deystviy psihologo-pedagogicheskogo sistemnogo analiza // Pedagogika i psihologiya segodnya: monografiya. Kniga 4/pod obsch.red. M. Yu. Buryikinoy - Stavropol: Logos, 2015.- p. 6 31.

8. Mischik SA (2016) Pedagogometricheskoe modelirovanie obrazovatelnoy deyatelnosti//Uspehi sovremennoy nauki i obrazovaniya. - 2016, \#8, Tom 1 - Belgorod, p.85-87.

9. Pechnikov AN, Vetrov YA (2002) Proektirovanie i primenenie kompyuternyih tehnologiy obucheniya. Ch.1. Kontseptsiya sistem avtomatizirovannogo obucheniya i modelirovanie protsessov deyatelnosti. Kn.1.SPb: BGTU, 2002.- 195 p.

10. Balyaeva SA, Uglova AN (2016) Innovative directions of the multi-level training program general scientific engineering and naval personnel [Текст]/С.А.Баляева, А.Н.Углова// Materialy Mezhdunarodnoy nauchnoy konferenctsii «Technological advances» 30.03.2016 ISJ Theoretical \& Applied Science, 03 (35): 146-148. Philadelphia, USA. http://dx.doi.org/10.15863/TAS.2016.03.35.241

11. Balyaeva SA (2016) Information model as a means of formation of professional integrity of knowledge of maritime transport [Текст] /С.А.Баляева // Materialy Mezhdunarodnoy nauchnoy konferenctsii «Global Science» 30.04.2016 ISJ Theoretical \& Applied Science, 04 (36): 141-143. Lancaster, USA. http://dx.doi.org/10.15863/TAS.2016.04.36.23 